\title{
Efek Penggunaan Beberapa Sinar $L E D$ pada Tanaman Buah Naga Merah (Hylocereus polyrhizus)
}

\section{ADHIATMA DHIYAN SAPUTRA, I GUSTI ALIT GUNADI*), DAN I WAYAN WIRAATMAJA}

\author{
Program Studi Agroekoteknologi Fakultas Pertanian Universitas Udayana \\ Jalan P.B. Sudirman Denpasar Bali 80231 \\ ${ }^{*}$ E-mail: gunadiya@gmail.com
}

\begin{abstract}
Effects of Using Multiple LED Beams on Red Dragon Fruit (Hylocereus polyrhizus). Red dragon fruit plant (H. polyrhizus) is a tropical plant and is very adaptable to growing environments and weather changes such as sunlight, wind, and rainfall. Dragon fruit plants is a long day plants (plants that require long enough sun exposure), which means that to produce this plant requires at least 12 hours of radiation. Knowing this, there needs to be a solution so that production stability can be controlled, one of which is by modifying the environment. The purpose of this study was to determine the effect of several colors of LED light (Light Emitting Diode) at the initiation stage of dragon fruit flowers in an effort to increase production. This study used a randomized block design with four treatments and nine replications, while the treatment consisted of control plants, the administration of white LED lights, yellow LED lights and blue LED lights. Three variables were observed, namely the number of flower buds, the number of blooming flowers and the number of young fruits. The results showed that the use of yellow LED lights give the best light intensity when compared to other treatments so that the yellow LED light treatment gave the best results on each variable including 6.44 pieces for flower buds, 7.56 pieces for flowers blooms and 7.56 pieces for young fruit.
\end{abstract}

Keywords: long day plant, light intensity, initiation

\section{PENDAHULUAN}

Indonesia sebagai salah satu negara penghasil komoditi pertanian tidak terlepas dari pengaruh yang mendukung perencanaan dan pelaksanaan pertanian (Andriana, 2013). Secara keseluruhan, buah naga baik untuk kesehatan dan dapat memenuhi kebutuhan tubuh akan zat gizi sehari-hari.

Tanaman buah naga sangat membutuhkan sinar matahari dengan intensitas di atas 90\%. Tanpa adanya sinar matahari yang cukup, tanaman ini sulit 
ADHIATMA DHIYAN SAPUTRA. et al. Efek Penggunaan Beberapa Sinar LED...

berkembang. Selain intensitas cahaya, lama penyinaran juga berperan penting. Tanaman buah naga termasuk long day plant (tanaman yang membutuhkan paparan sinar matahari cukup lama), artinya agar tanaman ini berproduksi, diperlukan penyinaran setidaknya 12 jam atau lebih. Tanaman buah naga tidak banyak dipengaruhi oleh angin, bahkan relatif relatif tahan terhadap kecepatan angin. Namun angin yang cukup kuat dapat merobohkan tiang rambatan. Solusi terhadap masalah ini adalah dengan membuat tiang rambatan yang permanen. (Warisno dan Kres Dahana, 2009).

Para petani menggunakan sinar lampu sebagai media peningkatan produksinya, lampu yang digunakan oleh para petani rata rata adalah lampu $L E D$ yang memiliki warna sinar putih dan kuning. Penambahan cahaya buatan untuk menciptakan kondisi hari panjang di daerah khatulistiwa dapat dilakukan dengan durasi tiga sampai empat jam pada intensitas cahaya kisaran 32-108 lux (Wiguna, 2015). Berdasarkan kekuatan intensitasnya, lampu $L E D$ biru merupakan lampu yang paling mendekati dengan nilai lux tersebut sehingga penulis menggunakannya sebagai acuan. Lampu LED yang digunakan dalam penelitian ada tiga macam warna yaitu putih, kuning dan biru. LED putih dipilih karena memiliki spektrum $P A R$ yang lengkap sedangkan $L E D$ kuning dan $L E D$ biru memiliki tingkatan range yang sama pada kekuatan panjang gelombang dari spektrum hijau (Narendra, 2012).

Tujuan penelitian ini adalah untuk mengetahui pengaruh sinar lampu LED terhadap munculnya bunga. Mengetahui sinar lampu $L E D$ yang paling efektif menstimulasi munculnya bunga.

Adapun hipotesisnya adalah sinar lampu LED mampu untuk menstimulasi munculnya bunga. Sinar lampu $L E D$ biru lebih efektif untuk menstimulasi pembungaan buah naga merah (H. polyrhizus).

\section{BAHAN DAN METODE}

Penelitian yang dilaksanakan di Dusun Sumberwaru, Desa Tamanagung, Kecamatan Cluring, Kabupaten Banyuwangi, Provinsi Jawa Timur pada ketinggian $99 \mathrm{~m} \mathrm{dpl}$. Penelitian ini dilaksanakan pada Bulan Juni sampai dengan Oktober 2018.

\section{Bahan dan Alat}

Bahan yang digunakan untuk menunjang penelitian ini yaitu, tanaman buah naga merah yang sudah berusia empat tahun, listrik, air irigasi, pupuk, data intensitas cahaya matahari Kecamatan Cluring (BMKG, 2018) 
Alat yang digunakan dalam penelitian ini adalah lampu $L E D 18$ watt sinar putih, lampu LED 18 watt sinar kuning, lampu LED 18 watt sinar biru, lux meter, plastik mulsa hitam perak, kamera telepon seluler, kabel, saklar, electrical insulation, pompa air, pipa spiral, pipa $P V C$, selang irigasi, altimeter, timer.

\section{Metode Penelitian}

Penelitian ini menggunakan Rancangan Acak Kelompok (RAK), terdiri atas empat perlakuan dengan sembilan kali ulangan. Perlakuan yang diujikan adalah tanaman tanpa sinar buatan sebagai kontrol, perlakuan dengan lampu LED 18 watt sinar putih (P) sebanyak satu lampu per tanaman, perlakuan dengan memasang lampu LED 18 watt sinar kuning (K) sebanyak satu lampu per tanaman, perlakuan dengan memasang lampu LED 18 watt sinar biru (B) sebanyak satu lampu per tanaman, jarak antara lampu dan tanaman $20 \mathrm{~cm}$ pada masing-masing perlakuan Tata letak percobaan dirancang sesuai dengan kaidah rancangan acak kelompok

Terdapat tiga variabel yang diamati yaitu jumlah kuncup bunga, jumlah bunga mekar dan jumlah buah muda lalu dilakukan pengamatan dan pencatatan sejak terjadi perubahan secara morfologis pada tanaman buah naga yaitu munculnya jumlah kuncup bunga, jumlah bunga mekar dan jumlah buah muda pada tiap masing-masing perlakuan dan tanaman kontrol untuk selanjutnya dilakukan perhitungan berupa analisis data hasil penelitian.

Data yang diperoleh dianalisis dengan sidik ragam atau analysis of variance (ANOVA). Apabila data hasil pengamatan nilainya sangat kecil atau terdapat data nol maka data tersebut ditransformasi ke akar kuadrat $\quad \sqrt{(x+1 / 2)}$ (Marzuki, 2005). Perlakuan yang berpengaruh nyata terhadap peubah yang diamati diuji lanjut menggunakan uji Beda Nyata Terkecil (BNT) pada taraf 5\%.

\section{HASIL DAN PEMBAHASAN}

Hasil sidik ragam menunjukkan bahwa pada perlakuan beberapa sinar lampu LED menunjukan pengaruh yang sangat nyata terhadap kuncup bunga pada minggu ketiga, bunga mekar pada minggu kelima dan buah muda pada minggu keenam (Tabel 1).

Perlakuan sinar lampu LED putih berpengaruh nyata terhadap kuncup bunga, akan tetapi tidak sebesar pengaruh lampu LED kuning (Tabel 2).

Bunga mekar pada minggu kelima $(7,56)$ paling banyak dihasilkan oleh pemberian lampu $L E D$ warna kuning dan berbeda nyata 
ADHIATMA DHIYAN SAPUTRA. et al. Efek Penggunaan Beberapa Sinar LED...

dengan lampu $L E D$ lainnya. Lampu $L E D$ berbeda nyata dengan lampu $L E D$ warna warna kuning juga menyebabkan buah muda putih, biru, dan kontrol (Tabel 2).

minggu keenam $(7,56)$ paling banyak dan

Tabel 1. Signifikansi Pengaruh Penggunaan Sinar Lampu LED terhadap Jumlah Kuncup Bunga, Jumlah Bunga Mekar, dan Jumlah Buah Muda.

\begin{tabular}{llc}
\hline No. & \multicolumn{1}{c}{ Variabel } & Sinar Lampu LED \\
\hline 1 & Kuncup Bunga Minggu Ketiga & $* *$ \\
2 & Bunga Mekar Minggu Kelima & $* *$ \\
3 & Buah Muda Minggu Keenam & $* *$ \\
\hline & Keterangan : $* *=$ Berpengaruh sangat nyata $\left(\mathrm{P}<\mathrm{F}_{0,01}\right)$ &
\end{tabular}

Tabel 2. Pengaruh Beberapa Sinar Lampu LED terhadap Jumlah Kuncup Bunga, Jumlah Bunga Mekar dan Jumlah Buah Muda.

\begin{tabular}{cccc}
\hline \multirow{2}{*}{ Perlakuan } & \multicolumn{3}{c}{ Variabel } \\
\cline { 2 - 4 } & $\begin{array}{c}\text { Jumlah Kuncup } \\
\text { Bunga Minggu } \\
\text { Ketiga } \\
\text { (buah) }\end{array}$ & $\begin{array}{c}\text { Jumlah } \\
\text { Bunga Mekar } \\
\text { Minggu Kelima } \\
\text { (buah) }\end{array}$ & $\begin{array}{c}\text { Jumlah } \\
\text { Buah Muda } \\
\text { Minggu Keenam } \\
\text { (buah) }\end{array}$ \\
\hline Tanpa Lampu & $0,00 \mathrm{a}$ & $0,00 \mathrm{a}$ & $0,00 \mathrm{a}$ \\
Lampu Putih & $4,33 \mathrm{~b}$ & $4.44 \mathrm{~b}$ & $4,33 \mathrm{~b}$ \\
Lampu Kuning & $6,44 \mathrm{c}$ & $7,56 \mathrm{c}$ & $7,56 \mathrm{c}$ \\
Lampu Biru & $0,00 \mathrm{a}$ & $0,00 \mathrm{a}$ & $0,00 \mathrm{a}$ \\
\hline BNT 5\% & 0,33 & 0,35 & 0,34
\end{tabular}

Keterangan : angka-angka yang diikuti oleh huruf yang sama pada kolom yang sama menunjukkan perbedaan yang tidak nyata pada uji BNT 5\%.

Kuncup bunga merupakan salah satu variabel yang digunakan sebagai indikator dan parameter awal dalam mengetahui tingkat efektivitas sinar lampu LED yang digunakan. Minggu ketiga pada pengamatan variabel kuncup bunga terlihat jelas pengaruh pada sinar lampu $L E D$ putih dan kuning yang sudah berusia lima hingga tujuh hari sementara pada kontrol dan sinar lampu $L E D$ biru jika dilihat dari jumlah kuncup bunganya tidak menunjukkan pengaruh. Kuncup bunga yang berusia dibawah lima hari rentan untuk gugur, sehingga pengamatan diutamakan pada kuncup bunga 
setelah terlihat (Gambar 1). Langkah tersebut diambil sebagai tindakan preventif agar data lapangan yang telah terinventarisasi efektif dan efisien jika terjadi gugurnya kuncup bunga, jadi jumlah untuk pengamatan pada variabel bunga mekar tidak jauh berbeda bahkan sama dengan variabel kuncup bunga yang telah dilakukan pengamatan.Untuk melihat lebih rinci pengaruh sinar lampu LED terhadap kuncup bunga dapat dilihat pada (Gambar 2).

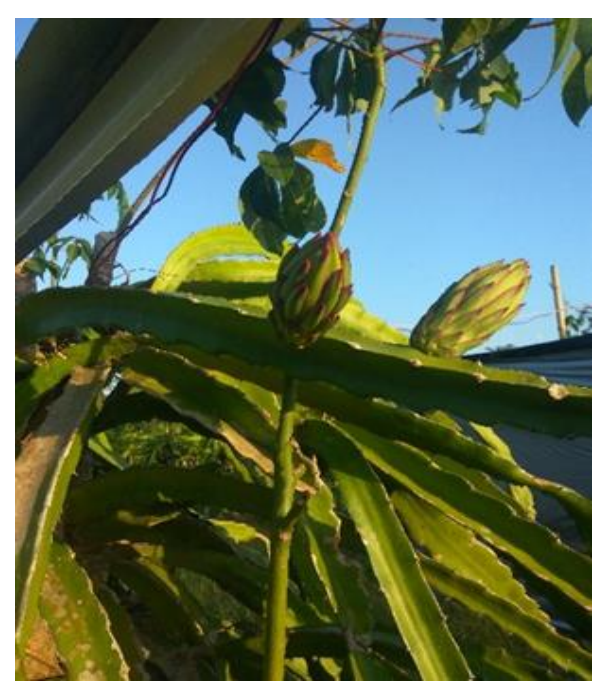

Gambar 1. Kuncup Bunga pada Pengamatan Minggu Ketiga.

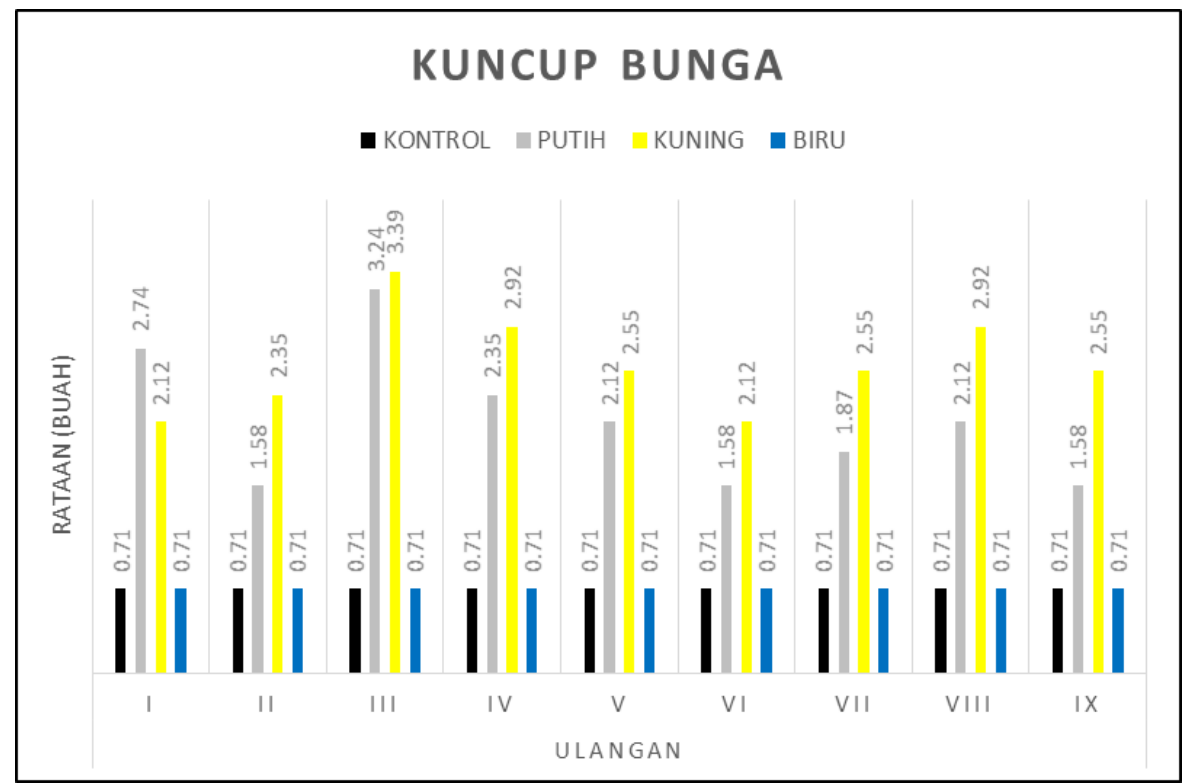

Gambar 2. Pengaruh Beberapa Sinar Lampu LED pada Variabel Jumlah Kuncup Bunga Minggu Ketiga 
ADHIATMA DHIYAN SAPUTRA. et al. Efek Penggunaan Beberapa Sinar LED...

Kuncup bunga yang berusia antara dilakukan dengan penyerbukan bantuan sepuluh sampai 14 hari akan memasuki fase manusia (manual) akan menghasilkan polinasi, kuncup bunga menjadi bunga mekar kualitas buah lebih baik dari sisi ukuran buah pada malam hari dan siap dilakukan sementara bunga yang penyerbukannya penyerbukan. Bunga mekar pada minggu secara alami ukuran buahnya dominan kecil. kelima mengalami peningkatan jumlah pada Penyerbukan (pollination) metode perlakuan lampu LED putih (P) dan lampu LED kuning (K), hal tersebut terjadi karena akumulasi dari kuncup bunga yang muncul setelah pengamatan minggu ketiga, sementara pada perlakuan (B) dan kontrol tidak menunjukkan perubahan. Upaya penyerbukan bantuan telah dilakukan dalam penelitian untuk peningkatkan kualitas buah manual yang dimaksud adalah penyerbukan dengan bantuan manusia, caranya adalah dengan mengambil sebagian serbuk sari yang berada di sekeliling putik lalu masukkan serbuk sari tersebut ke dalam lubang kepala putik, setelah sebuk sari dimasukkan tekan secara perlahan agar serbuk sari tidak tercecer dan masuk ke ovul (Gambar 3). yang dihasilkan, bunga buah naga yang

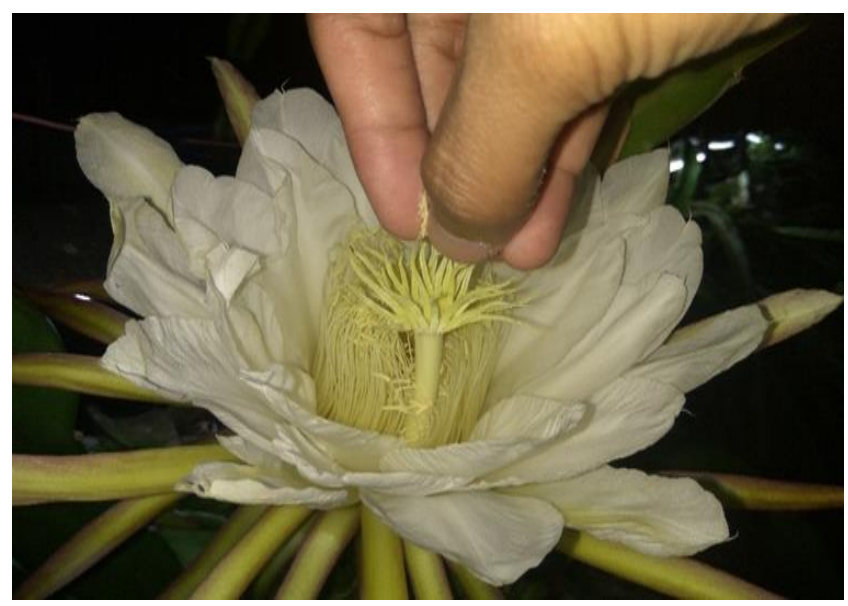

Gambar 3. Penyerbukan pada Bunga dengan Bantuan Manusia

Secara keseluruhan penyerbukan bantuan angin pada siang hari akan tetapi dilakukan secara manual seperti terlihat pada bantuan angin pada siang hari tidak gambar, ada penyerbukan secara alami yang sedemikian berpengaruh dikarenakan terjadi pada pagi hari yaitu ditandai dengan mahkota bunga buah naga sudah menutup. adanya bantuan lebah madu (Apis Linn) serta Perbandingan antara bunga yang terbentuk 
melalui penyerbukan manual dan secara manual menunjukkan ukuran buah penyerbukan alami terlihat perbedaan yang yang lebih besar jika ditinjau dari masa jelas pada ukuran morfologi buahnya dimana perkembangan buah muda hingga pada masa bunga dengan penyerbukan yang dilakukan siap panen.

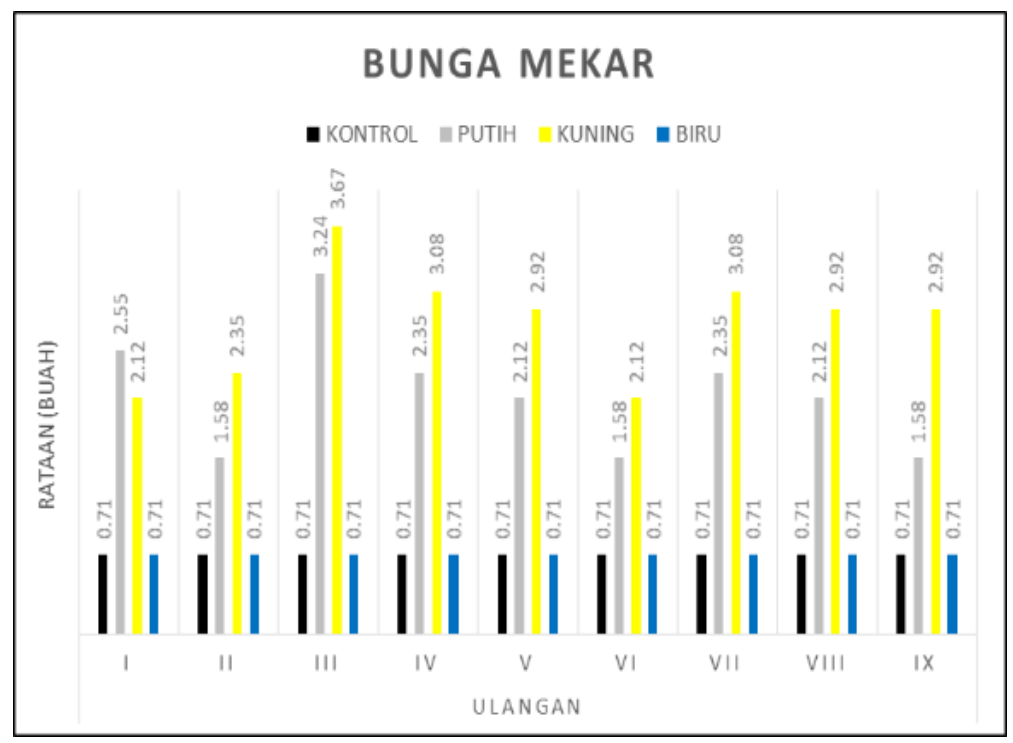

Gambar 4. Pengaruh Beberapa Sinar Lampu LED pada Variabel Jumlah Bunga Mekar Minggu Kelima

Grafik menunjukkan eskalasi pada dengan mahkota bunga yang telah busuk dan perlakuan sinar lampu LED kuning minggu mulai mengering (Gambar 5). Penurunan kelima dengan nilai rataan sebesar 3,67 pada jumlah buah muda pada perlakuan sinar ulangan ketiga sementara pada perlakuan lampu LED putih disebabkan gugurnya sinar lampu LED putih menunjukkan eskalasi nilai rataan sebesar 2,35 pada ulangan ketujuh.

Varibel penentu yang digunakan sebagai bunga setelah dilakukan penyerbukan. Ada beberapa faktor yang mengakibatkan gugurnya bunga setelah penyerbukan, faktor tersebut antara lain serangan hama, serangan parameter akhir penelitian adalah variabel penyakit dan gangguan pada fungsi fisiologis buah muda, kategori buah muda dapat dilihat tanaman itu sendiri. dari ciri morfologis buahnya yaitu ditandai 
ADHIATMA DHIYAN SAPUTRA. et al. Efek Penggunaan Beberapa Sinar LED...

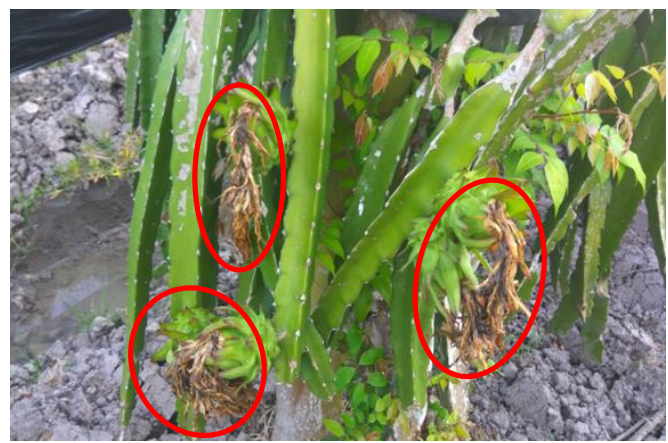

Gambar 5. Mahkota Bunga yang Telah Membusuk dan Mengering Dikategorikan dalam Buah Muda

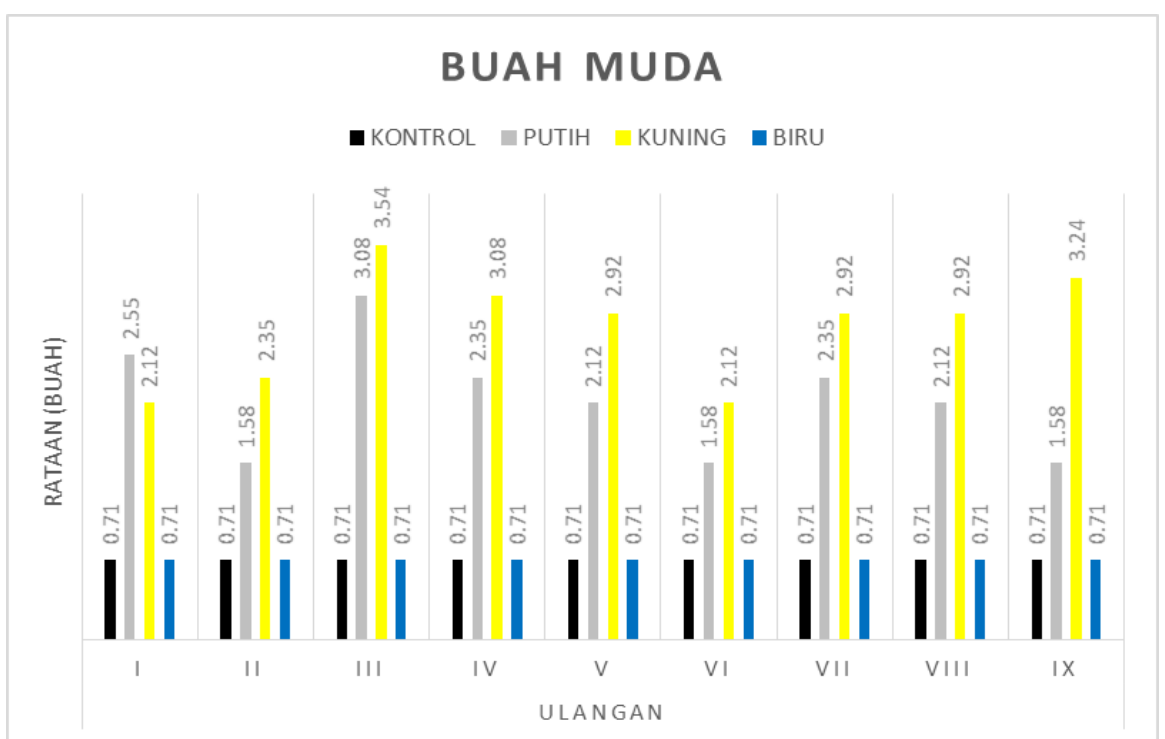

Gambar 6. Pengaruh Beberapa Sinar Lampu LED pada Variabel Jumlah Buah Muda Minggu Keenam

Tingkat keberhasilan pengaruh sinar nilai tertinggi 3538 lux, 880 lux untuk sinar lampu LED kuning dan putih tidak terlepas lampu LED putih dan 550 lux untuk sinar dari intensitas sinar yang diberikan terhadap lampu LED biru dihitung dari jarak terdekat tanaman, hal tersebut terjadi jika nilai lux tanaman $(20 \mathrm{~cm})$ dengan lampu pada jam yang diberikan oleh kekuatan masing-masing yang sama (19.46 WIB sampai 19.48 WIB). sinar lampu $L E D$ mendekati nilai lux yang Intensitas sinar lampu $L E D$ biru yang sangat dipengaruhi oleh intensitas sinar matahari. rendah mengakibatkan lambatnya proses Intensitas sinar matahari memiliki nilai stimulasi munculnya kuncup bunga. Hal tertinggi 10000 lux pada pukul 10.27 WIB tersebut diperkuat dengan data pada sementara sinar lampu $L E D$ kuning memiliki pengamatan minggu keenam yang 
menunjukkan adanya kuncup bunga yang muncul.

Nilai lux pada intensitas sinar matahari dan nilai lux pada masing-masing perlakuan untuk lebih jelasnya bisa dilihat pada perbandingan nilai lux (Gambar 7). Pada penjelasan sebelumnya terlihat bahwa nilai lux yang paling mendekati nilai lux sinar matahari adalah sinar lampu LED kuning, karena hal tersebut di ketiga variabelnya selalu memiliki jumlah paling banyak.

Gambar (a) yang merupakan nilai lux intensitas sinar matahari menunjukkan angka maksimal pada lux meter yaitu 10 ribu lux. Nilai lux tersebut diukur pada saat matahari mencapai puncak teriknya, penulis melakukannya pada pukul 10.27 WIB dimana keberadaan matahari yang tegak lurus (vertikal) tersebut yang digunakan penulis sebagai indikator pengukuran.

Pada gambar (b), (c) dan (d) masingmasing merupakan gambar nilai lux intensitas sinar lampu LED putih, kuning dan biru. Waktu pengukuran dilakukan pada malam hari pada pukul 19.46, 19.47 dan 19.48, dilakukannya pengukuran pada malam hari yaitu bertujuan untuk menghindari pengaruh dari radiasi sinar matahari sehingga nilai lux yang terekam merupakan murni dari pengaruh intensitas sinar lampu $L E D$.

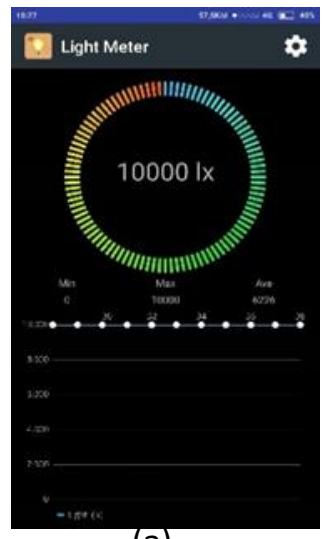

(a)

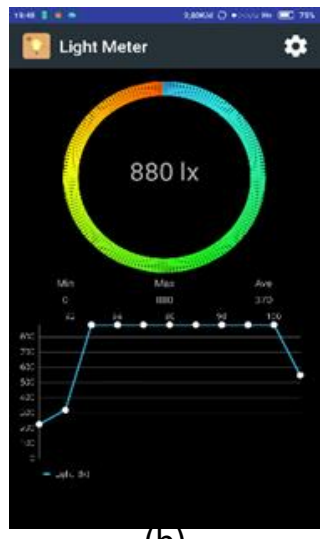

(b)

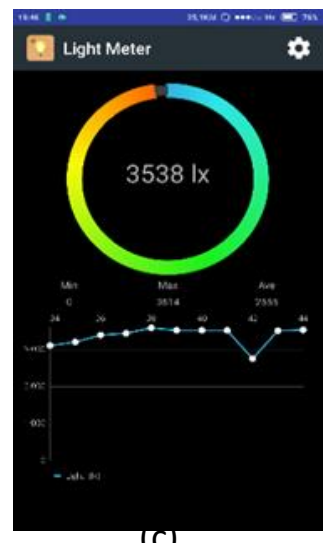

(c)

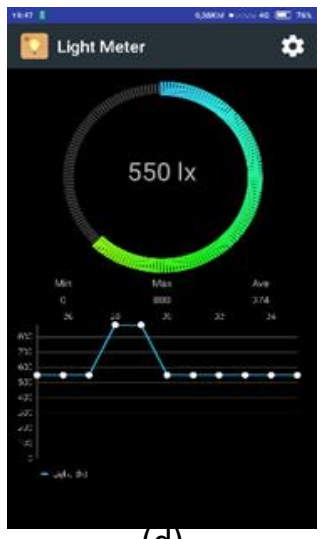

(d)

Gambar 7. (a) Nilai lux Sinar Matahari, (b) Nilai lux Sinar LED Putih, (c) Nilai lux Sinar LED Kuning, (d) Nilai lux Sinar LED Biru.

\section{SIMPULAN}

Berdasarkan hasil penelitian dan pembahasan tersebut dapat disimpulkan bahwa sinar lampu LED berpengaruh sangat nyata terhadap jumlah kuncup bunga, jumlah bunga mekar, dan jumlah buah muda. Sinar lampu LED kuning paling efektif untuk menstimulasi munculnya bunga buah naga 
ADHIATMA DHIYAN SAPUTRA. et al. Efek Penggunaan Beberapa Sinar LED...

merah (H. polyrhizus) dengan nilai masingmasing 6,44 buah untuk jumlah kuncup bunga, 7,56 buah untuk jumlah bunga mekar dan 7,56 buah untuk jumlah buah muda. Berdasarkan hasil penelitian dapat disarankan bahwa penggunaan lampu $L E D$ kuning paling efektif untuk menstimulasi kuncup bunga buah naga merah ( $H$. polyrhizus) dalam meningkatkan produksi. Penggunaan sinar lampu LED dengan intensitas cahaya yang lebih tinggi dapat menstimulasi kuncup bunga lebih cepat.

\section{DAFTAR PUSTAKA}

Andriana, 2013. Tanaman Komoditi di Indonesia. Diperoleh dari: http://digilib.unimed.ac.id/5440/9/9.\% 203113331029\%20Bab\%20I.pdf. Diakses pada 11 September 2017.

[BMKG] Badan Meteorologi, Klimatologi dan Geofisika, 2018. Lama Penyinaran dan Intensitas Cahaya Kecamatan Cluring. Banyuwangi. Stasiun BMKG Kelas III.

Narendra, 2012. Pengaruh PAR (Photosynthetic Activity Radiation) pada Tanaman. . Diperoleh dari : http://sustainablemovement.wordpres s.com/2012/03/08/ pengaruh-cahayaterhadap-pertumbuhan-tanaman/. Diakses pada 22 September 2017.

Warisno dan Dahana K., 2009. Buku Pintar Bertanam Buah Naga. Diperoleh dari: https://books. google.co.id/books?id=215nDwAAQ BAJ\&pg $=$ PR $3 \& l p g=P R 3 \& d q$. Diakses pada 14 Oktober 2019.
Marzuki, I. 2005. Aplikasi Minitab dalam Perancangan Percobaan di Bidang Agronomi. Universitas Pattimura, Ambon.

Wiguna I K.W., 2015. Respon Tanaman terhadap Penambahan Warna Cahaya Lampu LED Selama 30 Hari pada Fase Vegetatif terhadap Produksi dan Kualitas Bunga Krisan (Crhysantemum). Skripsi Universitas Udayana. Diperoleh dari :E-Journal /SKRIPSI\%20UN UD\%20 FIDES\%201992.pdf. Diakses pada 28 April 2018. 